\title{
THE INCREASING IMPORTANCE OF EFFECTIVE RISK MANAGEMENT IN BANKING -FINDINGS FROM SERBIA
}

\section{Dejan Vukosavljevic ${ }^{25}$, Danijela Vukosavljevic ${ }^{26}$, Gordana Jelic ${ }^{27}$}

\begin{abstract}
The subject of the research presented in this paper is risk management, with a special study of banking sector. Research goals include determining the degree of importance and influence of risk management of internal and external risks to a more favorable environment for business success of banks in strategic terms, in the long run. In this sense, the key results of the empirical research on the territory of Serbia in 2015 on a sample of 34 financial institutions, of which 26 were banks, has been provided. The results were processed by statistical and mathematical methods and confirmed the validity of the defined hypotheses, that the importance of effective risk management in banking is growing, as well as the reporting system. The contribution of this research is in a scientific assessment of the importance of various risks, determination of the dominant theoretical and empirical knowledge supporting wider further research in this area in the banking industry.
\end{abstract}

KEYWORDS: Banks, Risk management, Logistic regression, Reporting hierarchy, Non-performing loans

JEL: G21, G28, G31

UDC: 005.334:336.71(497.11)

\footnotetext{
${ }^{25}$ Faculty of Business Economics and Entrepreneurship, Belgrade, Serbia, e-mail: vukosavljevic.dejan@gmail.com

${ }^{26}$ Raiffeisen bank, Wiena, Austria

${ }^{27}$ Faculty of Technical Sciences, University of Priština (in Kosovska Mitrovica) Serbia
} 


\section{Introduction}

In modern conditions, especially in terms of the global banking business there are numerous risks that challenge the individual banking business, fee or at the very least a change that affects the outcome of the increasing uncertainty of the transaction, and generally increase the uncertainty of the realization of earnings. Achieving profitability in terms of increased competition and the growth of risk becomes a challenge for modern banking management, as well as for insurance (Piljan et al., 2014), and IT industry (Jevtic, Vucekovic, 2014). With the development of investment banking and the process of globalization of the financial system or the global operations of banks, there was an increase of additional risks that banks face in their operations. The global economic crisis, escalated in 2008 confirms this paper, when inadequate, unprofessional and somewhat hazardous behavior of the labor banking management, led to the mortgage crisis in the US, which is still reflected in the serious financial crisis in the world, and especially in the US and Europe, which is higher in order to protect the European Council adopted the directive on the protection of capital.

In 2013, the average total debt (earnings before interest, taxes, depreciation and amortization) increased significantly; loans with fewer restrictions such as stocks and income are also dramatically augmented. Banks use customer behavior before and after the crisis and modeled deposits. Smaller banks (according to EBRD data), in Europe have increased their long-term assets from $17 \%$ in 2006 to $31 \%$ in 2013 (Aleksic et al., 2014).

At the end of March 2015, the banking sector in Serbia is operated through the organizational network of 1,765 business units (22 fewer than at the end of 2014), with 24,753 employees (353 employees less than in the previous quarter).

Although all banks are independent legal entities which operate in accordance with local regulations conservative, developments in the euro area affect the banks in Serbia over the so-called: "psychological channel", (Farsi et al., 2014). The risks to the stability of the financial system - external and internal increase in the Serbian banking, international environment has reinforced its influence in particular: the introduction of sanctions, Russia and the sharp fall in oil prices, the strong depreciation of the ruble in late 2014 and the lowering of the credit rating. In Serbia there are four Greek banks, which at the end of 2014 had a total market share of about $14 \%$. The presence of Russian banks in Serbia is limited to two banks (market share of about $4 \%$ at the end of 2014). Thanks to strong domestic deposit base, which has shown growth resulting in a period of crisis and balanced measures of the National Bank of Serbia, the risk of external debt repayment, although present, is not at alarming levels and constantly monitored and analyzed.

According to the National bank's data, at the end of the first quarter of 2015, the banking sector in Serbia has expressed long open foreign exchange position in the amount of 14.1 billion dinars, while the foreign exchange risk at the level of $4.21 \%$. Banks in Serbia do business with net long positions in euros (10.41 billion) and US dollars (3.04 billion pounds), while in Swiss francs (1.44 billion pounds) have a net short position. The ten largest banks in Serbia by net balance sheet assets category, accounted for $76.2 \%$ of the total net assets of the banking sector in 2015 , with $75.5 \%$ and $78.0 \%$ in terms of total loans and total deposits of the banking sector. Banks criteria in terms of willingness to take risks are extremely high and the lack of quality demand is the main limiting factor for credit growth (especially in the economic sector).

The banks' position is: the most important foreign currency deposits, which in October 2015 , were worth 10.230 million euros, followed by capital and reserves (5,086 million euros), demand deposits (2.120 million euros), dinar savings and time deposits (1,557 million 
euros) and government deposits (EUR 451 million). These are the basic position of liabilities of commercial banks, which can be further divided by maturity of sources for financing business by economic sectors and other criteria (debit sources of financing). According to the Serbian National bank's date from 2015, non-performing loans (NPL) in the banking sector amounted to 426 billion dinars, or nearly 3.5 billion euros, what is an about 22 percent of total loans. Trends doubtful in non-performing loans demonstrate that for banks could be a very big problem. The methods of hedging should vigorously be more develop and implement, as illustrated by the data in the tables coming from the Balkans.

Although the reserve for estimated losses is still sufficient to NPLs do not threaten the stability of the financial system, the high share of these loans has a negative impact on the propensity of banks to take a risk and credit growth and represents a systemic risk. From the large number of variables that could affect the dynamics of NPLs, three in the case of Serbia demonstrated reliable predictable effect: (1) the exchange rate, (2) the seasonally adjusted real net wages and (3) the reference rate of interest. Lending and portfolio quality indicators show that the total net loans of the banking sector (in nominal value) at the end of 2015 increased compared to the previous period.

\section{Literature framework}

The phenomenon of risk has been mentioned in 1821 in the Arabic writings, in 1621 in the English documents, associating it with the possibility of loss, injury or other harmful or undesirable circumstances; as an opportunity or situation involving such a possibility (Alastair, 2010).

Many theorists define it differently, among which are significant:

According to Aven (2007), the risk is equal to two consequences dimension and associated uncertainties; The risk is the uncertain result of an event or activity in relation to the value (Rosa, 1998).

In the technical context, the concept of risk has a specific meaning. It is widely used in the causes, probability, or emergency that may, or may not occur, the decision on condition known probability. Terje and Ortwin (2009) are considered to be separated following common characteristics of risk: The risk is equated with the situation in which there is a possibility of occurrence of an adverse event. In economics, under the harmful event, risk means a loss, or an unexpected expense. From the theoretical point of risk, it is considered to be uncertainty about the outcome of an event, in a situation where there are two or more rival options. The banks, insurance, investment funds and other financial institutions are all faced with certain risks. Their task is to be properly directed and managed by them, in order to first of all take full advantage of the business enterprise, and losses to a minimum. In the banking sector, it is not only on the depositary function of banks, credit, investment, the dinar and foreign affairs, or any other function of work in the bank, but a subject of new regulatory of National banks, International financial institutions, Basel Agreements. The risks are very numerous and many times each causally connected and have an impact on the total business of the bank. The expansion of banks, especially investment banking influenced the expansion of the number of risks to which banks are exposed (Rose, Høyland, 2004). According to the International Standard Classification, each bank is mainly exposed to the following risks: credit, liquidity, payments, interest rate risk, foreign exchange, operational risks including IT and human resources' risks. 


\section{Research}

For the purpose of the paper, it has been realized an empirical field research in 2015, on the sample of 37 financial institutions, of which 24 banks in Serbia on the risk management issues were. An interview questionnaire has been compound of open and closed type of questions. Respondents were asked about the importance of individual risks, both internal and external. All the factors of risk are ranked according to their importance. Respondents have given answers also on how they consider the importance of an planned and continues reporting in risk management.

\section{Methodology}

The hypothesis of the research is defined as: H1. The importance of the effective risk management in the Banking increases. The hypothesis is validated by specific method of statistical analysis, which is quantitatively shown the impact of each risk factor on banks operations. The qualitative interpretation of the received responses analyzed in several ways by statistical methods was divided into further groups:

- The first group of statistical methods are the basic methods of descriptive statistical analysis of the observed data, certain dominant characteristics of the research sample, calculate the corresponding frequency response of individual subjects: the absolute and relative (percentage), the numerical parameters of the survey some basic statistical parameters, the mean and standard deviation for each of the hypotheses, and the poll question in the questionnaire;

- In the second group statistical test was used, depending on the individual variables of the sample, Pearson's $\chi^{2}$ (Chi-Square) test of independence of certain characteristics (of a given sample), and then in determining (in) dependence between the remaining individual responses of observed within the sample. For this purpose of the research an initial hypothesis (H0) of Independence characters. was introduced. It assumes that the value of the observed variables do not depend on the core business, which given bank performs.

- $\quad$ The analysis was made by the model of multiple regression analysis (Eng. Multiple Regression Analysis). The main role of this analysis is to describe the link between one output (dependent) and two or more input (independent) variables. Thus, it was constructed the corresponding multidimensional regression model, adjusted to given data, this is the most efficient, acceptable model describing the relationship between a set of independent variables that affect the value of the output end, the dependent variable. The goal of the was to find the model that is best suited to the data, or the most economical, but still acceptable model that describes the relationship between a dependent variable and a set of independent variables that describe it. In the paper, they are called-the proportion (share) of affirmative answers of respondents (responses are coded with "1"), the ratio of the number of these responses in relation to the total number of responses of all surveyed banks. In this way, the proportion is a special variable that characterizes the structure of the sample, or the respondents' answers to every single question survey, which is justified by the process of its introduction. 
For the regression coefficients, which are assessed on the basis of the data calculated in this research, it was used the original source code, i e. special series of software copyright procedures written in statistically-oriented programming language " $R$ ". This programming language is mainly designed and easier and simpler of statistical analysis.

On the basis of estimates of regression coefficients determined by the quantity and quality of the resulting regression, has been expressed the connection, degree of agreement logistical functions with empirically obtained, the observed data. To this end, it was used: Standard error estimates, the coefficient of determination, as quantitative indicators of the quality of the theoretical model which empirical data set "fits the" appropriate regression model. This scientific methods formally support the validity of the proposed hypotheses.

\section{Key research findings}

In statistical analysis of risk management, types of risks performed by banks, the internal and external risks have been analyzed. Table 1 , shows the total number of positive responses of 34 members (percentage), and the standard deviation for all eleven defined variables, i e. kinds of risk.

Table 1: Number of observations, the mean value and standard deviation of risk types of financial and banking companies

\begin{tabular}{||lllll||}
\hline Variables & $\begin{array}{l}\text { Types of risk } \\
\text { that the company follows }\end{array}$ & No. of positive responses & $\begin{array}{l}\text { Proportion } \\
(p)\end{array}$ & Stand. deviation \\
\hline$X_{1}$ & Market risk & 0 & 0,0000 & 0,0000 \\
$X_{2}$ & Strategic risk & 8 & 0,2353 & 0,1799 \\
$X_{3}$ & Risk of financial reporting & 18 & 0,5294 & 0,2491 \\
$X_{4}$ & Risk management & 17 & 0,5000 & 0,2500 \\
$X_{5}$ & Reputational risk (image) & 18 & 0,5294 & 0,2491 \\
$X_{6}$ & Human resources risk & 19 & 0,5588 & 0,2465 \\
$X_{7}$ & Operational risk & 16 & 0,4706 & 0,2491 \\
$X_{8}$ & Liquidity risk & 19 & 0,5588 & 0,2465 \\
$X_{9}$ & Credit risk & 10 & 0,2941 & 0,2076 \\
$X_{10}$ & Equity and funding risk & 18 & 0,5294 & 0,2941 \\
$X_{11}$ & Other & 10 & 0,2941 & 0,2076 \\
\hline \hline
\end{tabular}

Significantly, respondents expressed a positive attitude with respect to risk management in the broadest sense, encompassing very uniformly greater numbers of risk: the risks of human resources and liquidity, and the risks of financial reporting, reputation (image), capital and funding. All these risks in the process of governance has led more than half of the respondents, while exactly half of them singled out and risk management. This shows that banks and institutions in the banking sector are very dependent on the performance of its business of capital and financing, liquidity, reporting of financial interests which wrapped timely decision making and prevent the negative impact of risks, but also of quality staff and IT technology operational risks, which are becoming global growing opportunity lies and threats.

Table 2: Realized value. attitude scale (OR), legit function and the estimated value of coefficient of logistic regression (banking institutions). 


\begin{tabular}{|c|c|c|c|c|}
\hline Variables & Types of risk & OR & $\begin{array}{l}\text { Regression } \\
\text { coefficient }\end{array}$ & $\begin{array}{l}\text { Standar. } \\
\text { Error }\end{array}$ \\
\hline Regression constant & & & 0,3642 & 0,2917 \\
\hline$X_{2}$ & Strategic risk & 0,3077 & $-0,1623$ & 0,2084 \\
\hline$X_{3}$ & $\begin{array}{l}\text { Risk of financial } \\
\text { reporting }\end{array}$ & 1,1250 & 0,1512 & 0,1940 \\
\hline$X_{4}$ & $\begin{array}{l}\text { Risk management, } \\
\text { governance }\end{array}$ & 1,0000 & 0,0109 & 0,1945 \\
\hline$X_{5}$ & $\begin{array}{l}\text { Reputational risk } \\
\text { (image) }\end{array}$ & 1,1250 & 0,0620 & 0,1766 \\
\hline$X_{6}$ & Human resources risk & 1,2667 & 0,3205 & 0,1881 \\
\hline$X_{7}$ & Operational risk & 0,8889 & 0,3278 & 0,1753 \\
\hline$X_{8}$ & Liquidity risk & 1,2667 & 0,2440 & 0,1935 \\
\hline$X_{9}$ & Credit risk & 0,4167 & $-0,0745$ & 0,2117 \\
\hline$X_{10}$ & Equity and funding risk & 1,1250 & 0,4280 & 0,1948 \\
\hline$X_{11}$ & Other & \multirow[t]{4}{*}{0,4167} & \multirow[t]{4}{*}{$-0,0262$} & \multirow[t]{4}{*}{0,2764} \\
\hline Total eror $(Q)$ : & 0,2671 & & & \\
\hline Coefficient of determination $\left(R^{2}\right)$ : & 0,8751 & & & \\
\hline AIC: & 35,431 & & & \\
\hline
\end{tabular}

Displayed are observable values relations scale (OR-odds), then the estimated value of parameter logistic regression and, finally, the appropriate standard error estimates. All of these values, as in the case of the previous statistical regression analyze were obtained by software programming procedure, implemented in the programming language " $R$ ". Negative values of regression coefficients are present in variable unnamed types of risk, but partly related to strategic and credit risk.

On the other hand, the highest number of estimated values of coefficients of logistic regression, obtained from the above-mentioned software procedure, are positive, pointing to a positive correlation of these variables with the dependent, $i$ e. with the amount of total income of banks.

Looking at the size of the estimated positive regression coefficients, it is easily observed that particularly high value has the risk of equity and funding and right then, "shoulder to shoulder" following coefficients of operational risk, as well as the risk of human resources. Finally, it was emphasized that all quantitative indicators of quality achieved regression ties have again "favorable" numerical value.

By comparing the obtained values of regression coefficients can be seen that, different types of internal risks have different impacts on the operations of the surveyed banks. Risk average values are slightly more pronounced in risk capital and financing, and reputational image, while others are average values significantly lower and do not exceed the level of positive effects of $10 \%$. As expected, the most banks appointed at risk of equity and funding $(25.69 \%)$, followed by the positive impact of credit risk management (nearly $18 \%$ ). There is a significant and positive effect managing reputational and operational risk.

In the case of external risks significantly greater positive impact of risk management has at financial-banking institutions. The degree of correlation, expressed Pearson, varies depending on the type of researched risk. It is the most visible in the liquidity risk (99.92\%), while in the case of market risk and financial reporting correlation only slightly exceed $10 \%$. On this basis, it is clear that the management of a variety of internal and external risks of banks have specific impacts on their business, which were confirmed as accurate hypothesis. 
The validity of hypothesis $\mathrm{H} 1$ has been checked too, by special interviewing respondents about their perceptions of the importance of risk management and plans in the next period (2016 to 2018), to improve risk management. The majority of financial and banking institutions, risk management considers important or even very important (Figure 1).

\section{The importance of effective risk management}

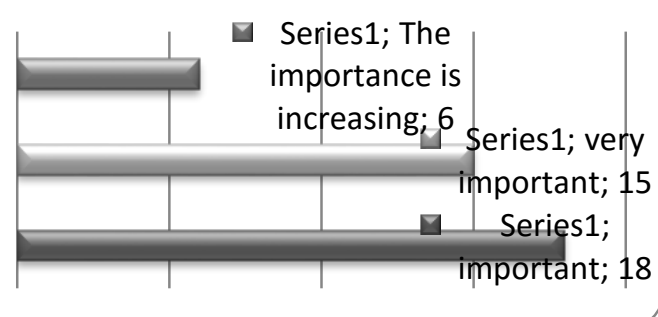

Figure 1: Diagram of respondents 'attitude on risk management importance (financial and banking institutions).

\section{Do you plan to improve risk management in the bank in therperiod, 2016-2018?

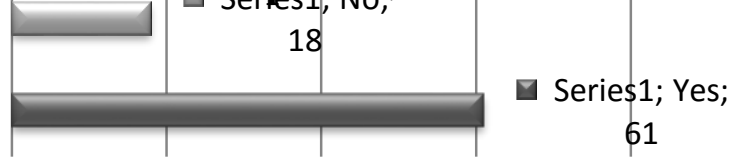

Figure 2: Diagram on risk management improvement plans

\section{Conclusions}

Key issues of risk in the banking industry, health and performance of banks, increased risk metrics and regulatory actions, pointing to the work of the strategic environment of high risk, competition from inside the industry and non-bank companies, low interest rates, changes in business models are more important issues for banking profitability and sustainability.

Because of that the research results presented in this paper are theoretical actual and funded. The research methods used are appropriate and validated the Hypothesis of the research, that the importance of effective risk management in banking is increasing.

It is also supported with increased regulatory penalties, increased sophisticated cyberattacks and information security risks, banks are faced with.

The risks in banks are typically the banking business, so there is no neutral banking transactions are not without risks and the adoption of new instruments, new techniques and strategies, financial engineering, new banking products, especially financial derivatives. For 
bankers and lenders in general, the uncertainty increases with changes in interest rates, changes in deposits and the borrower not able to serve its loan repayment obligations, but also under the influence of such factors as deregulation, moral hazard, as well as the entry of banks into tasks that previously were not traditional banking .

As a discipline, risk management is more recent and has evolved from the insurance business, because the traditional assurance processes could not effectively and economically solve the problems of risk in all situations.

\section{References}

[1] Alastair, J. (2012)."Oxford English Dictionary 'will not be printed again, The Telegraph.

[2] Aven T., (2007). "A unified framework for risk and vulnerability analysis and management covering both safety and security". Reliability Engineering and System Safety Vol. 92, pp. 745-754.

[3] Aleksic,V., Jerkovic, S., Ilic, S ( 2014). “ The first US intervention in Serbian economic reconstruction and recovery”, International Review, Vol. 3-4/2014, pp. 9

[4] Farsi, J.Y., Zare,B., Mahdi L.(2014)."Value Chains analysis for opportunity exploitation in software industry", International Review, Vol. 1-2/2014, pp. 45

[5] Jevtic,B., Vucekovic, M. (2014). "Techological Inovations, evidence from Serbia", International review, Vol. 3-4/2014, pp. 27

[6] Piljan I., Cogoljevic, D, Vujadin N.(2014). “ The participation on the Serbian Insurance Market”, International Review, Vol. 1-2/2014, pp. 136

[7] Rausand, M., Høyland A. (2004). System Reliability Theory: Models, Statistical Methods, and Applications, 2nd Edition, ISBN: 978-0-471-47133-2, John Wilev \& Sons. Inc, New Jersey

[8] Rosa, E.A. (2003). "The logical structure of the social amplification of risk framework (SARF): Metatheoretical foundation and policy implications". In N. Pidegeon, R.E. Kaspersen and P. Slovic (eds) The social amplification of risk. Cambridge: Cambridge University Press.

[9] Terje A., Ortwin, R. (2009). "On risk defined as an event where the outcome is uncertain”, Journal of Risk Research, Vol. 12, $\mathrm{N}^{\circ} 1$, pp. 1-11.

\section{Article history:}

- $\quad$ Received 25 April 2016

- $\quad$ Accepted 28 May 2016 